\title{
Studies on Effect of Different Environmental Conditions on CBR of Black Cotton Soil Reinforced with Coir Fibre
}

\author{
Akhileshwar Swami ${ }^{1}$, Pushpendra Kumar Kushwaha ${ }^{2}$ and Mohit Gangwar ${ }^{3}$ \\ ${ }^{1}$ Research Scholar, ${ }^{2}$ Assistant Professor, ${ }^{3}$ Principal \\ ${ }^{1,2}$ Department of Civil Engineering, RKDF College of Engineering, Bhopal, Madhya Pradesh, India \\ ${ }^{3}$ Bhabha Engineering Research Institute, Bhopal, Madhya Pradesh, India \\ E-Mail: mohitgangwar@gmail.com
}

\begin{abstract}
Expansive soil covers nearly 20 percent of the land mass in India. These soils are known to possess weak properties due to the presence of clay minerals known as "Montmorillonite". Typical behaviour of soil results in the failure of structures, in form of settlements, cracks etc. Thus it is important to remove the existing weak soil and replace it with non-expansive soil or to improve the properties of weak soil by stabilization. Soil reinforcement is a technique that can be used to improve the engineering characteristics of expansive soils. Use of natural fibres to reinforce soil is an old and ancient idea. Randomly distributed fibre reinforced soil have recently attracted growing attention in geotechnical engineering. The present dissertation aims to study the effect of different environmental conditions on performance of coir fibres included in black cotton soil to enhance its strength and reduce the swelling behaviour. Coir fibre is known as a biodegradable material that tends to decay under extreme environmental conditions such as in contaminated and polluted water, in getting contact with the leachate, in alternate cycles of wetting and drying, also in alternate cycles of freezing and thawing and so on. In general, life of coir fibre in soil is expected to 8-10 years. Therefore under different environmental condition it may degrade fast. The gain in soil strength or decrease in swelling might be lost. This aspect is not studied so far. Hence in this work this is attempted. The work in the project is experiment based, California bearing ratio of soil is an important soil strength parameter used in design of pavements. Effect of some different possible environmental conditions on CBR of expansive soil improved by coir fibre reinforcement will be studied experimentally in the present work.
\end{abstract}

Keywords: Expansive Soil, Soil Stabilization, Fiber Reinforcement, Coir Fiber, CBR

\section{INTRODUCTION}

Keeping in mind the large geographical area of India $(3,287,240$ sq. $\mathrm{km})$ and population of India (125 million approx.) a vast network of structures and roads are required (Singh and Mittal, 2014). The land available for construction purposes is very less because of increasing modernization and urbanization. From an ordinary house to sky scrapers, bridges to airports and village roads to highways or expressways everywhere land is being utilized. Owing to scarcity of ground, good for construction purpose, these days construction of structures is being carried on land with weak or soft soil. Stability of any structure depends on behaviour of soil under it. In case of construction in soft soil ground improvement by soil stabilization or soil reinforcement is usually adopted. Soil improvement enhances strength and makes it stable. (Chapale and Dhatrak, 2013)

During the last 25 years, much work has been done on strength deformation behaviour of soft soil reinforced with fibre. This has now been established beyond doubt that addition of fibre in the soil improves the overall engineering performance. Among the notable properties that get improved include greater extensibility, small loss in post peak strength, isotropy in strength and absence of planes of weakness. In the recent past fibre reinforced soil has been used in many countries and advance research is in progress for many hidden aspects of it. Fibre reinforced soil is seen to be effective in all types of soils (i.e. sand, silt and clay). The use of natural materials such as Jute, coir, sisal and bamboo, as reinforcing materials in soil is prevalent since long time and are abundantly used in many countries like India, Bangladesh, and Philippines etc. Main advantages of these materials are that they are locally available and very cheap. Being biodegradable they do not create disposal problems in the environment. (Singh and Bagra, 2013)

The foundation for a building or road is a vital part for effective transmission of load to the subsoil present underneath it. The quality of soil has large impacts on the type of structure and its design. Expansive soils are examples of weak soil, which when encountered in foundation engineering for buildings, highways, embankments etc. and come in contact with water; they undergo volume changes and show large swelling. They expand during rainy season and shrink during summer season.

Expansive soil covers nearly 20 percent of the land mass in India. These soils are known to possess weak properties due to the presence of clay minerals known as "Montmorillonite". Typical behaviour of soil results in the failure of structures, in form of settlements, cracks etc. Thus it is important to remove the existing weak soil and replace it with non-expansive soil or to improve the properties of weak soil by stabilization (Kharade et al, 2014). Soil reinforcement is a technique that can be used to improve the engineering characteristics of expansive soils. Use of 
natural fibres to reinforce soil is an old and ancient idea. Randomly distributed fibre reinforced soil have recently attracted growing attention in geotechnical engineering. (Hejazi et al, 2012). Further, soil stabilization using other waste materials should also be attempted thereby solving the disposal problem of wastes.

For sustainable development, the use of locally available materials and waste materials should be encouraged in order to preserve the natural resources for upcoming generation. Natural fibres can be easily obtained in many tropical regions and are available throughout the world. There are several types of natural fibres found in India like coir, bagasse, jute, oil palm, rice husk, sisal etc. Being good reinforcement material there is a need to concentrate on improving the properties of soil using cost-effective practices. (Barazesh, 2012)

Total world coir fibre production is about 250,000 tones. The coir fibre industry is particularly important in some areas of developing world. In India mainly the coastal region of Kerala State, produces $60 \%$ of the total world supply of white coir fibre. Sri Lanka produces 36\% of the total world brown fibre output. Over $50 \%$ of the coir fibre produced annually throughout the world is consumed in the countries of origin, mainly India. Together India and Sri Lanka produces $90 \%$ of the 250,000 metric tons of coir which is produced every year. (Dixit and Verma, 2012)

\section{A. Dissertation Work And Its Significance}

The present dissertation aims to study the effect of different environmental conditions on performance of coir fibres included in black cotton soil to enhance its strength and reduce the swelling behaviour. The coir fibre being biodegradable material will decay under extreme environmental conditions such as polluted water, contact with leachate, cycles of wetting and drying, cycles of freezing and thawing and so on. In general, life of coir fibre in soil is expected to 8-10 years. Therefore under different environmental condition it may degrade fast. The gain in soil strength or decrease in swelling might be lost. This aspect is not studied so far. Hence in this work this is attempted.

\section{B. Need of Study}

Coir fibre is a natural and biodegradable fibre. Due to the presence of high lignin content it is a strongest natural fibre. Under different environmental conditions the properties of the soil improved by coir will change, the assessment of which is necessary for planning better sustainability of treated soil. Hence there is a need to study this aspect.

The work in the project is experiment based, California bearing ratio of soil is an important soil strength parameter used in design of pavements. Effect of some different possible environmental conditions on CBR of expansive soil improved by coir fibre reinforcement will be studied experimentally in the present work.

\section{OBJECTIVES OF THE STUDY}

The prime aim of the present investigation is to assess the impact of environmental conditions on the strength of soil reinforced by coir fibres. The present investigation is aimed to achieve following objectives.

1. To study the effect of coir fibre content on CBR of expansive soil.

2. To study the effect of alternate drying and wetting on CBR of black cotton soil improved with coir fibre.

3. To study the effect of acidic water on CBR of black cotton soil improved with coir fibre.

4. To study the effect of leachate on CBR of black cotton soil improved with coir fibre.

5. To study the effect of freezing and thawing on CBR of black cotton soil improved with coir fibre.

6. To study the effect of water, acid and leachate on tensile strength of coir fibre.

\section{METHODOLOGY}

In order to achieve the above objectives a series of experiments are carried out on expansive soil sample with different percentages of coir fibre inclusion. Coir fibres are randomly distributed and $35 \mathrm{~mm}$ in length. In this study California bearing ratio tests are carried out with various percentages of coir fibres to optimum fibre content for CBR improvement and degradation of coir fibre under different environmental conditions. As a reference for making comparison, the above said tests are also carried out for unreinforced soil sample.

\section{LITERATURE REVIEW}

\section{A. Stabilization of Soil Using Coir Fibre}

Tiwar and Mahiyar, 2008, studied 48 trial samples, in two phases:- in first phase, the physical properties of soil such as hygroscopic moisture content, Atterberg's limits, grain size distribution, MDD-OMC, specific gravity, Direct shear test, Swelling pressure, CBR, Permeability test values were determined. In the second phase, various test investigation was performed on black cotton soil using different percentages of Fly Ash at 10\%, 15\%, 20\%, 25\%, Coconut Coir Fibre (CCF) at 0.25\%, 0.5\%, 0.75\%, 1\% \& Crushed Glass (CG) at $3 \%, 5 \%, 7 \%$ In these tests individual behaviour of FA.CG \& CCF with soil was also carried out which showed that for adding 10\%, 15\%, 20\%, 25\% \& $30 \%$ FA with soil, produced highest CBR of value 4 at maximum 25\%, after which curve height decreased gradually. Similarly on adding 3\%, 5\% \& 7\% they obtained highest CBR of value 3.1 at 7\% CG after curves went down enormously. Also for adding 0.25\%, 0.5\%, $0.75 \%, 1 \% \& 1.25 \%$ of CCR they obtained maximum curve height at CBR value of 3.6 after that curve showed successive depletion. Results for combinations made for 
25\% FA, 7\% \& 1\% CCF to set range for combination for this 48 trial samples were made. During the trial C.B.R, curve attained highest value at 5.2 and falls down 2.2 and again it went to 3.8, for different set of combination. The study showed that optimum combination is $20 \% \mathrm{FA}+5 \%$ CG +1 \% CCF with soil.

Chauhan et al, 2008, studied the effectiveness of fibre reinforcement (coir fibre and synthetic fibre) in subgrade soil from strength point of view. The permanent strain, resilient strain behaviour and resilient modulus of subgrade soil were determined in the laboratory. A value of $10 \%$ (20 $\mathrm{mm}$ ) strain was taken as the failure criterion for the subgrade for pavement in rural areas. A subgrade soil of silty sand mixed with optimum content of fly ash and two different types of fibres varying in their tensile strength and coefficient of frictions were used. Repeated triaxial tests on the samples, unreinforced and reinforced at optimum content of fibre, were carried out at confining pressures of 25, 50 and $75 \mathrm{kN} / \mathrm{m} 2$ and the stress levels of 153 and 204 $\mathrm{kN} / \mathrm{m} 2$, which produced six different deviator stresses. It was concluded that both the permanent and resilient strains in all materials decreased with confining pressure but increased with the number of load cycles and deviator stress in reinforced and unreinforced conditions. Moreover, the resilient modulus decreased with the number of load cycles and deviator stress and increased with the confining pressure. Coir fibre showed better resilient response against synthetic fibre by higher coefficient of friction.

Ramesh et al, 2010, conducted a series of Compaction and Unconfined Compressive Strength tests to study the effects of Randomly Distributed Coir Fibre (RDCF) inclusions and lime on geotechnical properties of $\mathrm{BC}$ soil as one combination and effect of bitumen coating on coir fibre reinforced $\mathrm{BC}$ soil as another combination. The UCS tests were conducted up to 180 days of curing. Indian brown colour coir fibre was mixed, in different proportions, with optimum percentage of lime to BC Soil. The strength increased up to 30 days linearly with the curing period, with further curing the increase was marginal. Optimum fibre of $1.0 \%$ (by weight) with $0.5 \mathrm{~cm}$ length was identified for improving the strength of BC Soil. From UCS test with 180 days of curing it was found that addition of bitumen coated coir fibre in BC soil was less beneficial.

\section{B. Degradation of coir fibre in stabilized soil under different conditions}

\section{Effect of Heat}

Khan and Alama, 2012 investigated the degradation behaviour of untreated and treated fibre by varying time and temperature. It was observed that the DP (degree of polymerization) of fibre decreased with increase in temperature and time. At low temperatures, the rate of degradation was lower but at higher temperature degradation occurred very rapidly. The intrinsic viscosity of fibre decreased with the progress of time, which corresponded to the decrease in DP. The degradation of fibre up to $180^{\circ} \mathrm{C}$ was studied and was found that at higher temperature DP decreased to a great extent. After heating for 4 hours at $180^{\circ} \mathrm{C}$, loss of DP value was $19.4 \%$ for untreated fibre, $10.4 \%$ for sodium hydroxide treated fibre and $11.5 \%$ for sodium chlorite treated fibre. But the degradation of fibre below $140^{\circ} \mathrm{C}$ was very low. Time also affected the degradation process. In this study after heating the fibre at $180^{\circ} \mathrm{C}$ for $1 \mathrm{~h}$, it showed a decrease in DP of $3.2 \%$ for untreated fibre, $2.6 \%$ for sodium hydroxide treated fibre and $3.1 \%$ for sodium chlorite treated fibre of its original molecular weight. But when it was heated at the same temperature for 5 hours DP decreased to $23.6 \%$ for untreated fibre, $12.1 \%$ for sodium hydroxide treated fibre and $15.0 \%$ for sodium chlorite treated fibre. When fibre was heated, owing to thermal fluctuation, the energy of thermal motion at some point of the system became commensurable with the energy of chemical bond and this resulted in the rupture of chemical bond. The C-C bond is one of the most resistant bonds to thermal influences. The presence of hydrogen atom in polymer molecule greatly decreased the energy of C-C bond and that high molecular mass hydrocarbon like fibre possesses comparatively showed lower stability and hence easily degraded by heating. The untreated fibre contains higher amount of lignin than sodium hydroxide treated fibres and sodium chlorite treated. Hence, the degradation was more prominent in untreated fibre. After heating for 4 hours at $180^{\circ} \mathrm{C}$ the loss in tensile strength was about $28.6 \%$ for untreated fibre, $18.4 \%$ for sodium hydroxide treated fibre and $20.8 \%$ for sodium chlorite treated fibre. Again the loss of tensile strength of fibre below $120^{\circ} \mathrm{C}$ was very low. The melting point of lignin was $120^{\circ} \mathrm{C}$. So, when fibre was heated at $120^{\circ} \mathrm{C}$ or above, the lignin molecules began to melt with the rupture of the incrustants and hence the loss in tensile strength became higher. In general, higher temperature or longer duration of exposure leads to increase in depolymerization and drop in tensile strength. After 5 hours heating in oven, the loss of tensile strength becomes $36.4 \%$ for untreated fibre, $24.6 \%$ for sodium hydroxide treated fibre and $27.5 \%$ for sodium chloride treated fibre. After 5hours heating, all the lignin of fibre was oxidized. For maximum exposure condition used with $180^{\circ} \mathrm{C}$ for 5 hours, the drop of tensile strength was found to be roughly $36.4 \%$ for untreated fibre, $24.6 \%$ for sodium hydroxide treated fibre and $27.5 \%$ for sodium chloride treated fibre.

\section{Effect Of Leachate}

Arasan, 2010 defined the Leachate as liquid that has percolated through solid waste and has extracted, dissolved or suspended materials. In majority landfills leachate is composed of liquid that has entered the landfill from external sources, such as surface drainage, rainfall, groundwater, and water from underground springs and the liquid produced from the decomposition of the wastes, if any. When water percolates through solid wastes which are undergoing decomposition, both biological materials and chemical constituents are leached into the solution. 
Chemical composition of the leachate will vary significantly depending on the age of the landfill and the events before the time of sampling.

Mukkulath and Thampi, 2012, studied coir geotextiles media degradation primarily intended to obtain some insight into the influence of substrate concentration in influent wastewater, to a biofilter on the attached media. Results showed that reduction in tensile strength of coir geotextile media fibres increased with substrate concentration in the influent wastewater. This could be because of the growth of microorganisms influenced by availability of the substrates. Nevertheless, these microorganisms cause media degradation. Influent $\mathrm{pH}$ also influenced the tensile strength of the coir geotextile media. . Permittivity was also affected by the concentration of substrates in the influent. Suspended solids in the influent may be intercepted in the pores of the coir geotextile medium, thereby restricting flow of the influent through the filter.

\section{Effect Of Alternate Wetting And Drying}

Hegde and Daware, 2010 studied the shear strength parameters of lateritic soils and the effect of alternate wetting and drying on these parameters. The soil sample was dried for 24 hours and saturated for 1, 2, 5, 10, 15 and 21days, and the shear parameters were evaluated. Also, the effect of alternate wetting and drying on Atterberg limits was studied. From the study it was found that after a number of alternate wetting and drying cycles, the lateritic soil started losing its strength as compared to the initial strength. Bearing capacity increased with increase in alternate wetting and drying cycles but after few numbers of cycles the rate of increase of bearing capacity reduced drastically and thus there is reduction in the bearing capacity. Alternate wetting and drying cycle also affected the liquid limit and plastic limit of lateritic soil. Both liquid limit and plastic limit decreased with increase in the number of alternate wetting and drying cycles.

\section{Effect Of Alternate Freezing And Thawing}

Hazirbaba and Gullu, 2010 studied that geotechnical properties of soils were affected by extreme ground temperatures. Freezing and thawing considerably decreased soil stability. In cold regions decreased shear strength and stability of soils after winter seasons, known as thaw weakening, is a common engineering problem. Other common geotechnical problem encountered in cold regions was frost heave, typically observed in fine-grained materials. As voids within fine-grained soils gets exposed to low temperatures, pore-water transforms into ice particles. When the soil is fully frozen (i.e., water within the voids between soil particles are completely frozen), the volume of water increases approximately by $9 \%$ resulting in unavoidable cracks in soil. The strength of the soil decreases as size and number of cracks increases. Freezethaw cycling is a weathering phenomenon which is normal in cold climates and considerably changes the structure of soils and has great influence on engineering properties of the soil such as physical features including hydraulic permeability, unfrozen water content, densification and mechanical features involving strength, bearing capacity, compressibility. Loose soils tends to be densified and dense soil become looser after freeze-thaw cycles and both the loose and dense soil may attain the same void ratio after a number of cycles. Having increased the large pores that are left after the thaw of ice crystals, permeability will increase. These cycles reduce the ultimate strength of soil.

Ghazavi and Roustaei, 2013 studied that in freeze cycles, translocation of water and ice that can be caused by thermodynamic conditions at temperatures just below $0^{\circ} \mathrm{C}$, changes the engineering properties of the soils. UU Triaxial compression tests were performed to investigate the effect of freeze-thaw cycles on strength properties of soil reinforced with geotextile layer. A clayey soil, reinforced with a geotextile layer located at mid-height of the sample, was compacted in the lab and subjected to a maximum of 9 closed-system freeze-thaw cycles. Computerized tomography (CT) images were taken from the samples. It was found that unconsolidated untrained triaxial compressive strength of unreinforced soil decreased with increasing the number of freeze-thaw cycles, whereas reinforced samples showed better performance and strength reduction amount decreased from $43 \%$ to $14 \%$ by reinforcing soil. CT images showed that free water moved through the soil particles towards the lower part of the soil samples. Additionally, it was found that sample reinforcement can reduce the effect of freeze-thaw cycles on changes of cohesion and resilient modulus of the soil. Separations of soil aggregates caused by ice lenses, made of soil pure water at temperatures below $0{ }^{\circ} \mathrm{C}$, disrupt the interlocking of soil grains and change the mechanical properties of the soil.

Ghazavi and Roustaie, 2013, conducted UU triaxial tests to investigate the changes of soil mechanical features after freeze-thaw cycles. As seen, in all reinforced and unreinforced samples, by increasing freeze-thaw cycles, the soil strength decreased. However, the strength decrease was more pronounced in unreinforced samples than in geotextile-reinforced ones. When reinforced with geotextile stress-strain variations of thawed clay tend to vary from strain-softening type to strain-hardening type.

Ghazavi and Roustaie, 2013 were performed lab test to demonstrate the influence of freeze-thaw cycles on compressive strength of a reinforced clayey soil. The results showed that:

1. By increasing the number of freeze-thaw cycles, the strength of all reinforced and unreinforced samples decreased. The effect of freeze-thaw cycles was more pronounced in unreinforced samples compared to the reinforced ones.

2. Existence of a nonwoven geotextile layer in the middle of soil sample height reduces the freeze-thaw influence 
as the greatest strength reduction has been reduced from $43 \%$ to $14 \%$ after the 9 th cycle by sample reinforcement.

3. Resilient modulus of soil decreased by about $40 \%$ of unfrozen soil resilient modulus in unreinforced samples and $60 \%$ in the samples which were reinforced by a geotextile layer after 9 freeze-thaw cycles.

4. The cohesion in the pure and reinforced soil decreased by increasing the number of freeze-thaw cycles, but by reinforcing the samples with geotextile layer, reduction trend of cohesion \ reduced from $72.3 \%$ to $15.6 \%$. Internal friction angle remained almost constant with increasing the number of freeze-thaw cycle.

5. Based on the changes in strength and height of samples subjected to 1-9 freeze-thaw cycles, it can be concluded that most of the changes occurred from 1st to 7 th cycles.

6. One of the most common effects of freeze-thaw cycles was the height increase after the cycles. The results showed that the height of both unreinforced and reinforced soil samples increased after the cycles, but most of the changes occur at 1st to 6th cycles and a little more for unreinforced samples compared to others.

Hazirbaba and Gullu, 2010, conducted CBR tests for freezing and thawing conditions in addition to non-freezing conditions. The improvement of soil was tested with the inclusion of: i) geofibre only, ii) synthetic fluid only, and iii) synthetic fluid and geofibre together. Both unsoaked and soaked samples were investigated to represent unsaturated and saturated soil conditions for various field applications. The results for unsoaked conditions indicated major improvement in the CBR performance, particularly for samples treated with geofibre and synthetic together. For soaked conditions, the best performance was obtained from the samples treated with geofibre only. The CBR performance of samples subjected to a freeze-thaw cycle was also tested. Freezing and thawing tests on unsoaked samples showed that the addition of geofibre together with synthetic fluid was generally successful in providing resistance against freeze-thaw weakening. Addition of synthetic fluid alone was not effective against the detrimental impact of freeze-thaw. The results from soaked samples subjected to a freeze-thaw cycle showed poor CBR performance for treatments concerning synthetic fluid while samples improved with geofibres alone generally produced better performance.

Hazirbaba and Gullu, 2010, conducted an extensive experimental study to investigate the improvement in CBR strength and freeze-thaw performance of low plasticity fine-grained soil treated with geo fibre and synthetic fluid. The major conclusions of this study were:

1. The optimum geo fibre content for the soil tested was found to travel between the dosages of $0.2 \%$ and $0.5 \%$ depending on sample condition and geo fibre type. For unsoaked conditions $0.2 \%$ fibrillated geo fibre or $0.5 \%$ tape geo fibre was recommended as optimum content.
For soaked conditions, a dosage rate of $0.5 \%$ was found to yield optimum performance for both geo fibre types.

2. Optimal performances from samples treated with synthetic fluid only were obtained at a dosage rate of $4 \%$.

3. A combined use of $0.5 \%$ geofibre and $4 \%$ synthetic fluid along with $6 \%$ water content provided a substantial improvement in the CBR performance, and appears to be an optimum combination for the treatment of the silt.

4. The results suggested that for applications that can be represented by unsoaked samples conditions treatment with synthetic fluid alone was effective and sufficient. Though, this is not true for soaked conditions due to the hydrophobic nature of the synthetic fluid.

5. Freezing and thawing tests showed that the treatment with geofibre and synthetic fluid was effective against the detrimental effects of the freeze-thaw process. Improved performances were obtained particularly for unsoaked conditions and the results from soaked samples showed that geo fibre alone was more effective in providing resistance against strength loss induced by freeze-thaw.

6. The curing tests on soaked samples that were subjected to freeze- thaw cycle showed no improvement in CBR strength with time, which implied the ineffectiveness and poor performance of the synthetic fluid in the presence of water.

Shivraja et al., 2010, maintained the temperature from $0^{\circ} \mathrm{F}$ to $40^{\circ} \mathrm{F}$ and $40^{\circ} \mathrm{F}$ to $0^{\circ} \mathrm{F}$ for 4 hours. Heating was done in oven and cooling was done in the freezer. Cylindrical specimens of $150 \mathrm{~mm}$ diameter and $300 \mathrm{~mm}$ height for conventional, coir $1.5 \%$ and sugarcane $1.5 \%$ mixes were cast and cured for 28 days. The cured specimens were then allowed for accelerated curing for 2 years. Then specimens were allowed for 300 numbers of freezing and thawing cycles. At the end of every 30 freezing and thawing cycles, the specimens were tested to acquire mass loss (\%) and relative modulus of elasticity (\%). Due to the experimental facility limitation, static modulus of elasticity was found and used instead of dynamic modulus of elasticity.

\section{Effect Of Acid Rain}

Sharma et al, 2012 studied that the acid rain results in changes in physico-chemical characteristics of soil due to cations exchange. $\mathrm{pH}$ of the soil decreases. Grain size distribution of the soil shifts towards silt fractions when subjected to acid rain. The angularity of individual particles also increases. AR affects the consistency properties of the soil and leaching of cations reduces the attractive forces between soil particles which lowers the overall strength of soil. Continuous addition of air pollutants like sulphur dioxide, oxides of nitrogen etc. not only pollutes the atmosphere but also indirectly causes degradation of lithosphere. These gases are major source of acid rain whose $\mathrm{pH}$ may be as low as 3 to 4 . Frequent, persistent and growing intensity of acid rain certainly exceeds buffering 
cation exchange capacity of soil which enhances the rate of leaching of cations from soil to a great extent. Absorption of $\mathrm{H}+$, SO42-, NO3- and CO32- by the soil particles will alter physico-chemical and engineering properties of soil which cannot be ignored. Thus it is imperative to examine the properties of soils eroded due to acid rain in order to augment understanding of its influence on geotechnical engineering. To monitor the degree of variation in texture, physicochemical and engineering properties of soil of different plasticity are exposure to acid rains of varying strength have been taken up.

Umesh et.al, 2011 to study the influence of acid rain on the soil properties, soil fraction passing $4.75 \mathrm{~mm}$ sieve was shaken for 8 hours with varying probable simulated strength of acid rain equivalent to normality $0.005 \mathrm{~N}, 0.01 \mathrm{~N}, 0.02 \mathrm{~N}$ and $0.04 \mathrm{~N}$ of H2SO4, HNO3 and 1:1 mixture of H2SO4 / HNO3 (expected composition of acid rain). Acidification lowers the cation exchange capacity, affects the grain size distribution and alters the consistency as well as strength properties of the soil.

Acid contaminations of soil even at low concentrations adversely affect the geotechnical properties of soil. The effect of sulphuric acid contamination (0-15\%) on the behaviour of three types of soils- black cotton soil, a dispersive soil called Suddha soil and a red loamy soil with varied clay content was studied. Specific surface of all the soils decrease due to acid contamination. The liquid limit decreased for all the three soils with increase in sulphuric acid concentration generally due to increase in electrolyte concentration of the pore fluid and consequent decrease in the thickness of double layer developed. This indicated the reduction in water holding capacity and increase in the frictional resistance and decrease in cohesion in soil. With increase in acid concentration the cation exchange capacity of soils decreased. There was a decrease in optimum moisture content of soil.

Umesh et al, 2011 studied that the Unconfined compressive strength significantly reduced due to loss of cohesion. The mechanical behaviour of soil predominantly depends on the mineralogical composition, physicochemical interaction between particles, pore fluid chemistry, inter particle forces and soil structures. Therefore there is a need to understand the geotechnical behaviour of acid contaminated soils.

Acidification of rain caused by air pollutants like sulphur dioxide and oxides of nitrogen etc. reduce the $\mathrm{pH}$ to as low as 3 to 4 . The low $\mathrm{H}+$ concentration of acid rain falling for a short duration may not affect soil properties instantaneously due to adequate cation exchange capacity of soil. But the frequent, persistent and growing intensity of acid rain will certainly exceed buffering capacity of the soil. This will enhance the rate of leaching of cations in the soil to a great extent. Absorption of $\mathrm{H}+$, SO42-, NO3- and CO32- by the soil particles will alter physical, chemical and engineering properties of soil which cannot be uncared for. Therefore it is imperative to examine the properties of soils eroded due to acid rain in order to augment understanding of its influence on geotechnical engineering.

\section{MATERIAL}

1. Black cotton soil

2. Coir fibre

3. Acid

4. Leachate

\section{RESULTS}

For stabilization of BC soil, coir fibre with $0.25 \%$, $0.50 \%$, $0.75 \%, 1 \%$ and $1.25 \%$ are randomly distributed in soil. CBR of black cotton soil when coir fibre was randomly distributed in different percentages are given in table I.

TABLE I CBR OF B.C. SOIL WITH DIFFERENT \% OF COIR FIBRE

\begin{tabular}{|c|c|}
\hline Coir \%(gm) by weight of soil & Soaked CBR \\
\hline $0.25 \%$ & 3.06 \\
\hline $0.50 \%$ & 3.28 \\
\hline $0.75 \%$ & 3.50 \\
\hline $1 \%$ & 3.72 \\
\hline $1.25 \%$ & 3.50 \\
\hline
\end{tabular}

From above table we can see that the soaked CBR value was maximum with $1 \%$ of randomly distributed coir fibre. Soaked CBR was increased by $32.6 \%$ with the addition of $1 \%$ of coir fibre. Variation in CBR values with increasing coir fibre percentage is shown in fig. 4.1. So in this project for degradation purpose we will use soil stabilized with $1 \%$ of randomly distributed coir fibre.

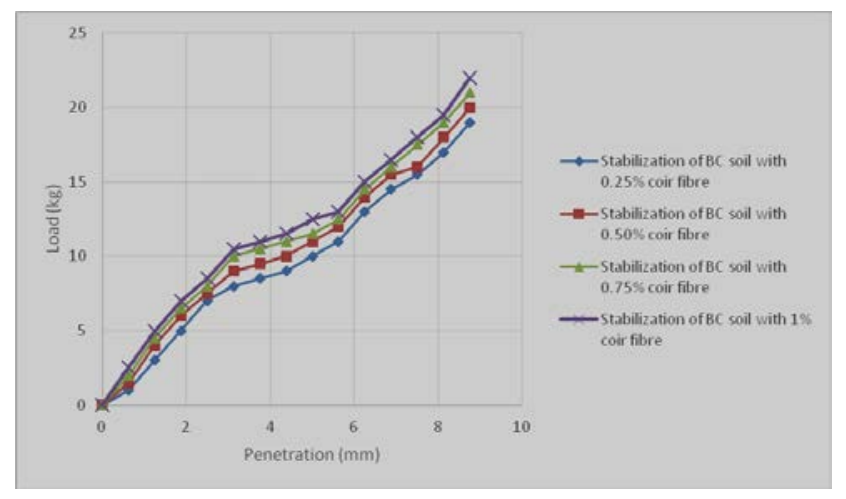

Fig. 1 Variation in soaked CBR of Black Cotton Soil with increase in coir fibre percentage

\section{A. Alternate soaking and drying in water}

CBR mould of black cotton soil was prepared without coir fibre and with $1 \%$ of coir fibre. Prepared CBR Mould was kept in water for soaking purpose for 24 hours and for drying purpose it was kept in oven at 500C for 24 hours. The process of alternate soaking and drying was done for 7 days, 14 days and 28days. CBR value decreases with 
increase in time and the variations in CBR value with coir fibre and without coir fibre are shown in given table II.

TABLE II CBR OF B.C. SOIL AFTER ALTERNATE SOAKING AND DRYING IN WATER

Time (Days) Water + Soil Water + Soil + Coir

\begin{tabular}{|c|c|c|}
\hline 7 & 2.81 & 3.5 \\
\hline 14 & 2.62 & 3.28 \\
\hline 28 & 2.4 & 3.06 \\
\hline
\end{tabular}

After a number of alternate wetting and drying cycles, black cotton soil starts losing its strength as compared to the initial strength. Bearing capacity increases with increase in alternate wetting and drying cycles but after few no of cycles the rate of increase of bearing capacity reduces drastically and thus there is reduction in the bearing capacity. Alternate wetting and drying cycle also affect the liquid limit and plastic limit of lateritic soil. Both liquid limit and plastic limit decreases with increase in the number of alternate wetting and drying cycles.

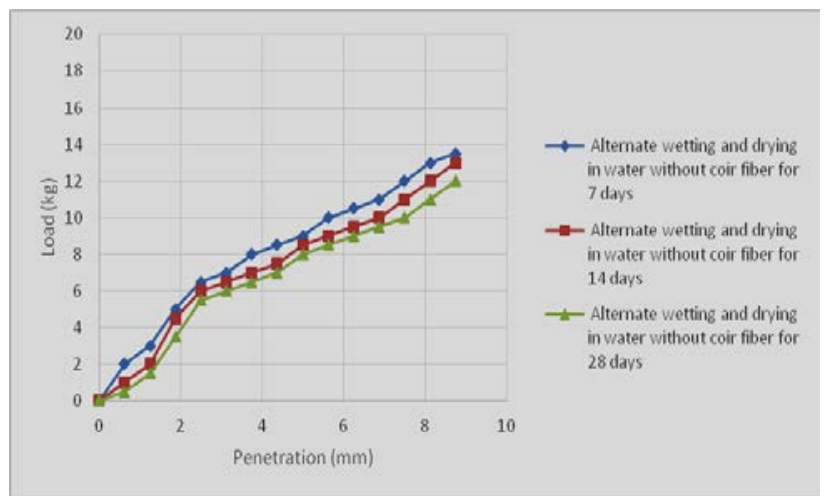

Fig. 2 Variation in CBR of Black Cotton Soil without coir fibre after alternate wetting and drying in water for different time periods

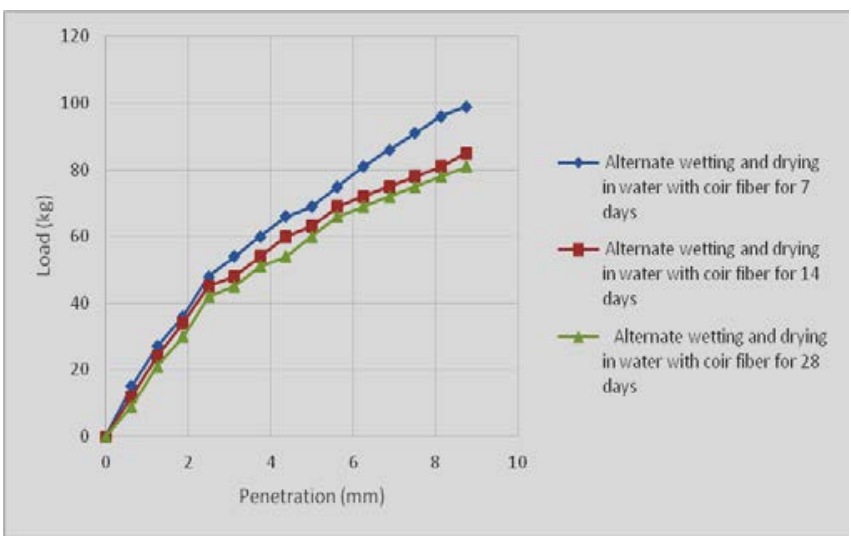

Fig. 3 Variation in CBR of Black Cotton Soil with coir fibre after alternate wetting and drying in water for different time periods

\section{A. Alternate soaking and drying in acid}

CBR mould of black cotton soil was prepared without coir fibre and with $1 \%$ of coir fibre. Prepared CBR Mould was kept in sulphuric acid with $0.6 \mathrm{ml} / 5 \mathrm{l}$ of distil water for soaking purpose of 24 hours and for drying purpose it was kept in oven at 500C for 24 hours. The process of alternate soaking and drying was done for 7 days, 14 days and 28days. CBR value decreases with increase in time and the variations are shown in given table III.

TABLE III CBR OF B.C. SOIL IN ACID ON ALTERNATE SOAKING AND DRYING

\begin{tabular}{|c|c|c|}
\hline Time(Days) & Acid + Soil & Acid + Soil +Coir \\
\hline 7 & 2.41 & 2.84 \\
\hline 14 & 2.18 & 2.67 \\
\hline 28 & 1.97 & 2.18 \\
\hline
\end{tabular}

The liquid limit decreased for black cotton soil with increase in sulphuric acid concentration generally due to increase in electrolyte concentration of the pore fluid and consequent decrease in the thickness of double layer developed. This indicates the reduction in water holding capacity and increase in the frictional resistance and decrease in cohesion in soil. With increase in acid concentration the cation exchange capacity of soils decreases. There is a decrease in the optimum moisture content of soils. Unconfined compressive strength has significantly reduced due to loss of cohesion. CBR value of $\mathrm{BC}$ soil decreases with increase in time.

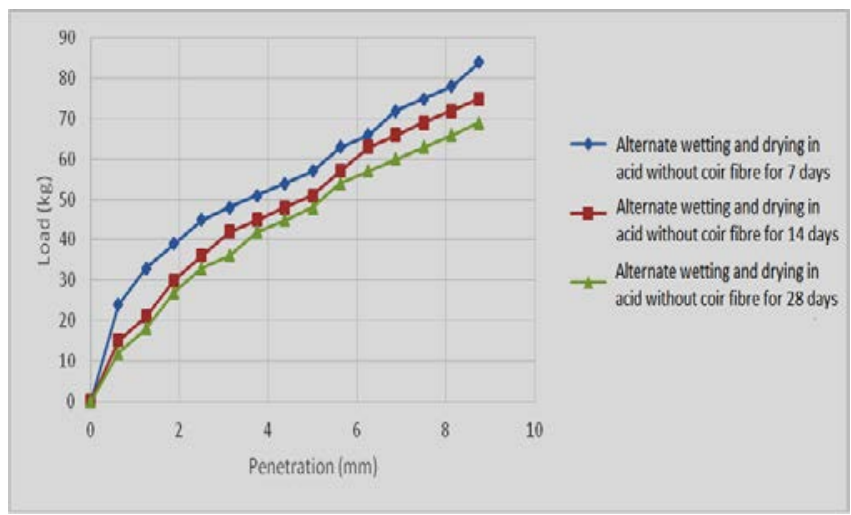

Fig. 4 Variation in CBR of Black Cotton Soil without coir fibre after alternate wetting and drying in acid for different time periods

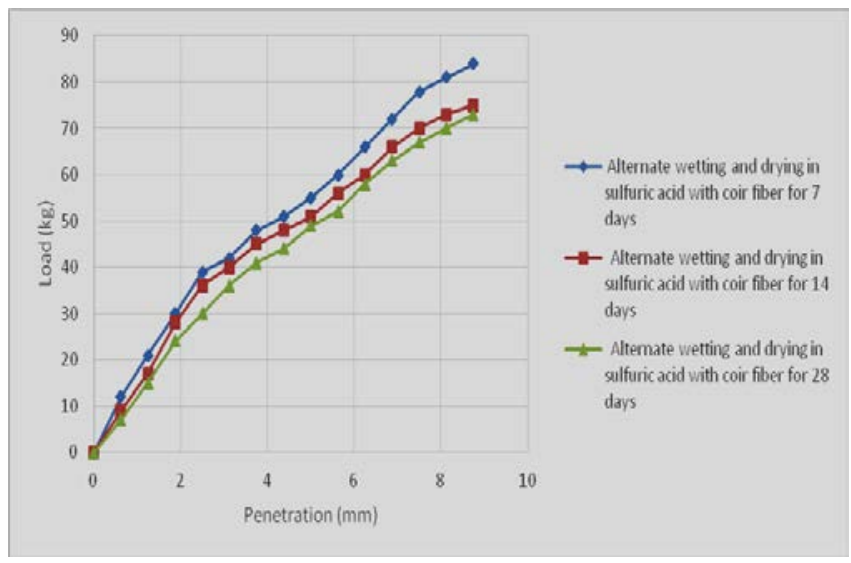

Fig. 5 Variation in CBR of Black Cotton Soil with coir fibre after alternate wetting and drying in acid for different time periods 


\section{B. Effect of alternate wetting and drying in leachate}

CBR mould of black cotton soil was prepared without coir fibre and with $1 \%$ of coir fibre. Prepared CBR Mould was kept in leachate for soaking purpose of 24 hours and for drying purpose it was kept in oven at 500C for 24 hours. The process of alternate soaking and drying was done for 7 days, 14 days and 28days. CBR value decreases with increase in time and the variations are shown in given table IV.

TABLE IV CBR OF B.C. SOIL AFTER ALTERNATE SOAKING AND DRYING IN LEACHATE

\begin{tabular}{|c|c|c|}
\hline $\begin{array}{l}\text { Time } \\
\text { (days) }\end{array}$ & Leachate +Soil & $\begin{array}{c}\text { Leachate +Soil + } \\
\text { Coir }\end{array}$ \\
\hline 7 & 2.62 & 3.28 \\
\hline 14 & 2.4 & 3.06 \\
\hline 28 & 2.18 & 2.62 \\
\hline
\end{tabular}

Reduction in tensile strength of coir geotextile media fibres increases with the substrate concentration in the influent wastewater. This could be because growth of microorganisms is influenced by availability of substrates. However, these microorganisms cause media degradation. Influent $\mathrm{pH}$ also influences the tensile strength of the coir geotextile media. Permittivity is also affected by the concentration of substrates in the influent. Suspended solids in the influent may be intercepted in the pores of the coir geotextile medium, thereby restricting flow of the influent through the filter.

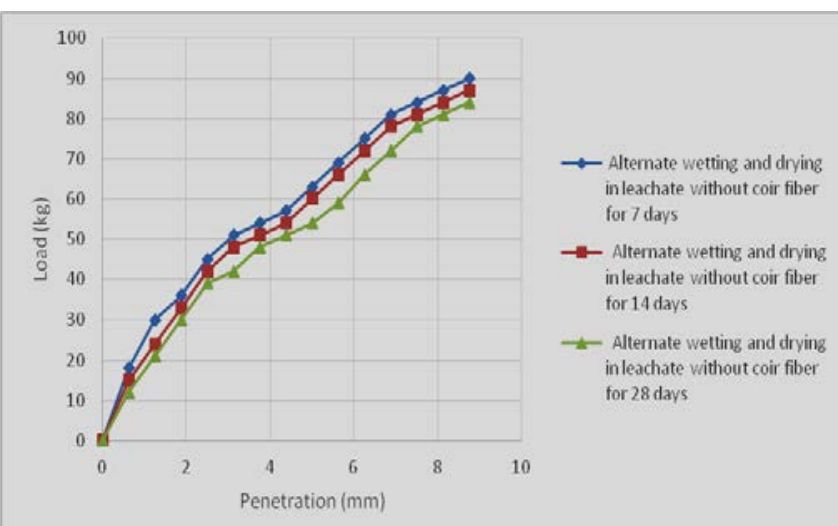

Fig. 6 Variation in CBR of Black Cotton Soil without coir fibre after alternate wetting and drying in leachate for different time periods

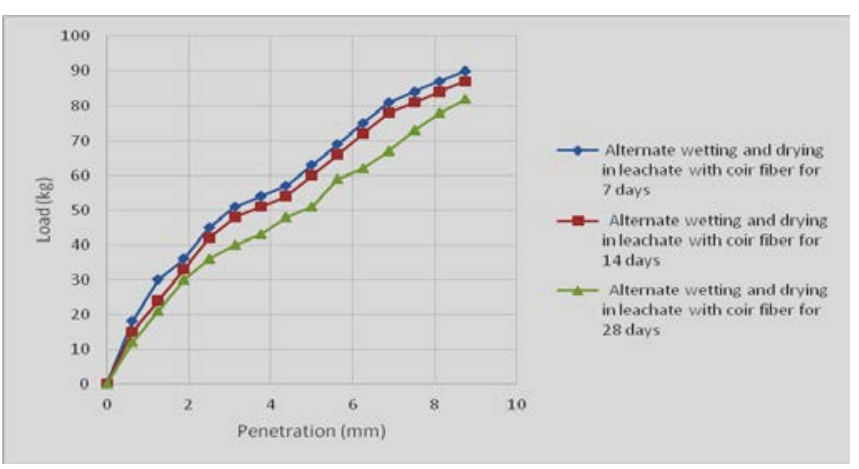

Fig. 7 Variation in CBR of Black Cotton Soil with coir fibre after alternate wetting and drying in leachate for different time periods

\section{Effect of alternate freezing and thawing}

CBR mould of black cotton soil was prepared without coir fibre and with $1 \%$ of coir fibre. Prepared CBR Mould was kept in refrigerator for freezing purpose of 24 hours and for thawing purpose it was kept at room temperature for 24 hours. The process of alternate soaking and drying was done for 7 days, 14 days and 28days. CBR value decreases with increase in time and the variations are shown in given table V.

TABLE V CBR OF B.C. SOIL ON ALTERNATE FREEZING AND THAWING

\begin{tabular}{|c|c|c|}
\hline $\begin{array}{c}\text { Time } \\
\text { (Days) }\end{array}$ & $\begin{array}{c}\text { Soil on freezing } \\
\text { and thawing }\end{array}$ & $\begin{array}{c}\text { Soil + Coir fire on } \\
\text { freezing and thawing }\end{array}$ \\
\hline 7 & 10.07 & 14.06 \\
\hline 14 & 6.86 & 8.75 \\
\hline 28 & 3.5 & 4.5 \\
\hline
\end{tabular}

After alternate freezing and thawing, it is clear that strength decrease is more pronounced in unreinforced samples than in stabilized ones. Soils tend to densify and dense soils become looser after freeze-thaw cycles and both loose and dense soils may attain the same void ratio after a number of cycles. Having increased the large pores that are left after the thaw of ice crystals, permeability will increase .These cycles reduce the ultimate strength of soil. Separation of soil aggregates which is caused by ice lenses, made of soil pure water at temperatures just below $0^{\circ} \mathrm{C}$, disrupts the interlocking of soil grains and changes the mechanical properties of soil.

TABLE VI ALternate FREEZING AND THAWING

\begin{tabular}{|c|c|c|}
\hline Time(Days) & Soil & Soil+ Coir fibre \\
\hline 7 & 10.07 & 11.824 \\
\hline 14 & 6.86 & 7.84 \\
\hline 28 & 3.5 & 4.06 \\
\hline
\end{tabular}

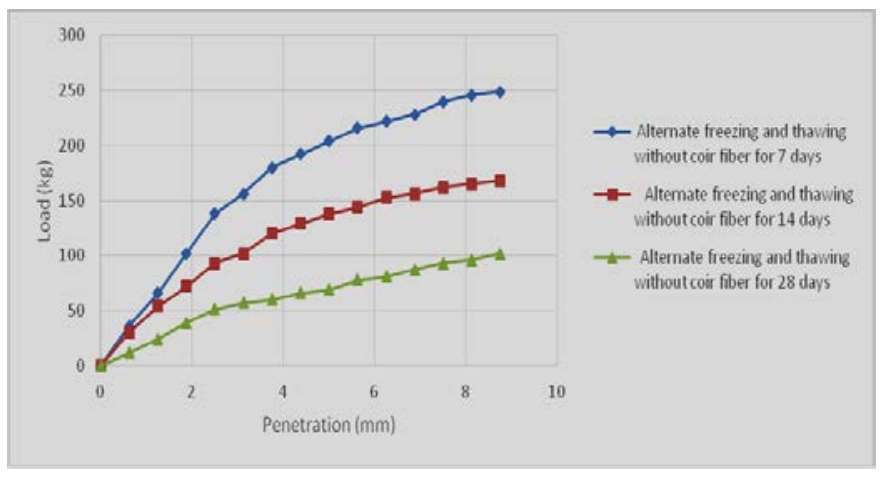

Fig.8 Variation in CBR of Black Cotton Soil without coir fibre after alternate freezing and thawing in water for different time periods 


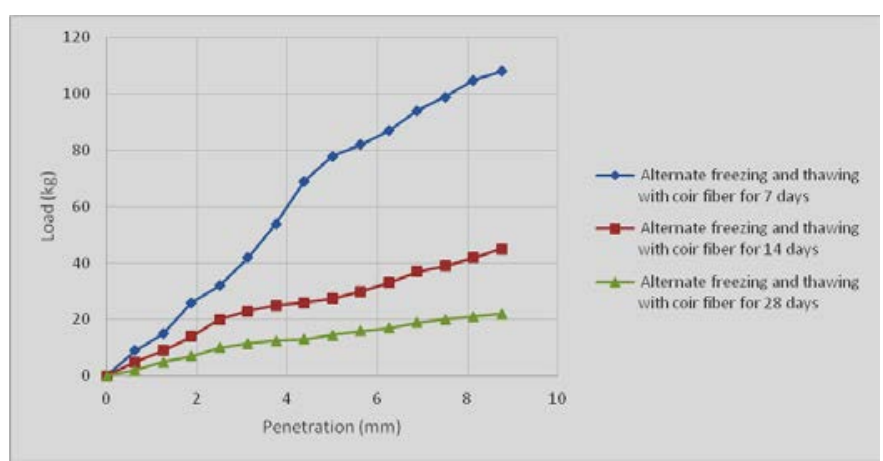

Fig. 9 Variation in CBR of Black Cotton Soil with coir fibre after alternate freezing and thawing in water for different time periods

\section{CONCLUSION}

The work conducted in the current dissertation can be summed up as the following:

1. Soaked CBR value of BC soil was 2.82 and with $1 \%$ coir fibre (by weight) soaked CBR value was 3.72, i.e. increased by $31 \%$.

2. On alternate wetting and drying, degradation of coir fibre was maximum in sulphuric acid and minimum in water. The coir tensile strength initially was $18 \mathrm{~N} / \mathrm{mm} 2$, which reduced to $15.5 \mathrm{~N} / \mathrm{mm} 2,14 \mathrm{~N} / \mathrm{mm} 2$ and 11 $\mathrm{N} / \mathrm{mm} 2$, by alternate drying wetting for 30 days in water, lechate and sulphuric acid respectively.

3. Sulphuric acid not only reduces tensile strength of coir fibre but the CBR of BC soil too.

4. On alternate wetting and drying in leachate, degradation was more than water but less than acid and after 28 days CBR of stabilized was decreased by $30 \%$ and it was less than original CBR of black cotton soil. So it is less advantages to use coir fibre in landfill site area.

5. On alternate freezing and thawing, CBR of stabilized soil and unstabilized soil was increased drastically by $269 \%$ and $254 \%$ respectively and decreases with time but not less than original CBR of BC soil. So on alternate freezing and thawing, overall CBR value of stabilized soil and unstabilized soil has increased. So we can use coir fibre for stabilization purpose in cold areas.

6. On alternate wetting and drying in acid, CBR of stabilized soil and unstabilized soil decreases with increase in time but after 14 days and 28 days CBR was very less and decreases to $29 \%$ and $35 \%$ respectively than original CBR of BC soil. So coir fibre is not useful for stabilization in acid rain prone areas.

\section{REFERENCES}

[1] Ghavami K, Filho R, Barbosa P., “ Behaviour of composite soil reinforced with natural fibres”, Cement Concrete Compos, Vol. 21, pp. 39 - 48, 1999.

[2] Bujang I. Z., Awang M. K. and Ismail A. E., "Study on the Dynamic Characteristic of Coconut Fibre Reinforced Composites", Regional Conference on Engineering Mathematics, Mechanics, Manufacturing \& Architecture, Malaysia, 2007.

[3] Chauhan Mahipal Singh, Mittal Satyendra, Mohanty Bijayananda, "Performance evaluation of silty sand subgrade reinforced with fly ash and fibre", 2008.

[4] Guntur, Suresh K., Padmavathi V., Sultana Apsar , "Experimental study on stabilization of black cotton soil with stone dust and fibres", IGC 2009.

[5] Ahmad F, Bateni F, Azmi M., "Performance evaluation of silty sand reinforced with fibers", Geotext Geomember, Vol. 28, No. 93, pp. 9, 2010.

[6] Chaple Parag M and Dhatrak A I., "Performance of Coir fibre Reinforced Clayey Soil”, The International Journal of Engineering and Science (IJES), Vol. 2, No. 4, pp. 54-64, 2010.

[7] H.N Ramesh., K.V. Krishna, H.V. Manoj Mamatha, "Effect of LimeCoir Fibre on Geotechnical Properties of Black Cotton Soil”, Indian Geotechnical Conference - 2010, GEOtrendz, pp. 16-18, 2010.

[8] Hazirbaba Kenan and Gullu Hamza, ,California, "Bearing Ratio improvement and freeze-thaw performance of fine-grained soils treated with geofibre and synthetic fluid”, Cold Regions Science and Technology, Vol. 63, pp. 50-60, 2010.

[9] Hassan Wan Hasmida Binti Wan, "Strength Characteristic of Soft Soil Reinforced With Coir Fibres”, 2010.

[10] Hegde R. A. and Daware S.N., "Effect of Alternate Wetting and Drying on Laterite and Their Engineering Behaviour", Indian Geotechnical Conference - 2010, pp. 16-18, December 2010.

[11] Jamellodin Z, Talib Z, Kolop R, Noor N., "The effect of oil palm fibre on strength behaviour of soil", In: 3rd SANREM conf, kota kinabalu, Malaysia, pp. 3-5 August, 2010.

[12] Ayothiraman R. and Meena Ablish Kumar, "Improvement of Subgrade Soil with shredded waste tyre chips”, Proceedings of Indian Geotechnical Conference Kochi (Paper No. H- 033), pp. 15-17, December 2011,

[13] Dixit Savita and Verma Preeti, "The effect of surface modification on the water absorption behaviour of coir fibres", Pelagia Research Library. Advances in Applied Science Research, Vol. 3, No. 3, pp. 1463-1465, 2012.

[14] Hejazi Sayyed Mahdi, Zadeh Mohammed Sheikh, Abtahi Sayyed Mahdi and Zadhoush Ali, "A simple review of soil reinforcement by using natural and synthetic fibres", Construction and Building Materials, Vol. 30, pp. 100-116. 2012.

[15] Amadi A. A, Eberemu, A. O., Momoh, O. H., "Use of Coir Fibre Reinforcement Technique to Improve Strength of Cement Kiln Dust Treated Black Cotton Soil Subgrade”, Geosynthetics, Long Beach, California, pp. 1-4, April, 2013.

[16] Chavan Apurva J, "Use of plastic waste in flexible pavements", International Journal of application or innovation in Engineering and Management, Vol. 2, No. 4, April 2013.

[17] Ghazavi Mahmoud, Roustaei Mahya, "Freeze-thaw performance of clayey soil reinforced with geotextile layer", Cold Regions Science and Technology, Vol. 89 , pp. 22-29, 2013.

[18] Hambirao Ghatge Sandeep , Rakaraddi P.G., "Soil Stabilization Using Waste Shredded Rubber Tyre Chips”, IOSR Journal of Mechanical and Civil Engineering (IOSR-JMCE) e-ISSN: 22781684,p-ISSN: 2320-334X, Vol. 11, No. 1 Ver. V Feb., pp. 20-27, 2014. 